\title{
Uso de rejeito da dessalinização na solução nutritiva da alface, cultivada em fibra de coco ${ }^{1}$
}

\author{
Nildo da Silva Dias ${ }^{2 *}$, Antonio Gilberto de Oliveira Jales ${ }^{3}$, Osvaldo Nogueira de Sousa Neto ${ }^{4}$, \\ Maria Isidória da Silva Gonzaga ${ }^{5}$ Ítalo Sorac Rafael de Queiroz, ${ }^{6}$ Maria Alice Formiga Porto ${ }^{6}$
}

\section{RESUMO}

A escassez de água de boa qualidade na região semiárida leva ao uso de água salobra para a irrigação. Este trabalho teve como objetivo avaliar o efeito do uso de rejeito da dessalinização na solução nutritiva, sobre a produção da alface (Lactuca sativa L.), cultivada em sistema hidropônico com o substrato fibra de coco. O ensaio foi desenvolvido em um ambiente protegido do Departamento de Ciências Ambientais, da Universidade Federal Rural do Semi-Árido, em Mossoró-RN, instalado em delineamento experimental de blocos ao acaso, em esquema fatorial com cinco x dois tratamentos e três repetições, testando-se cinco níveis de salinidade da solução nutritiva, obtidos com ou sem a necessidade de diluição da água de rejeito da dessalinização (CE 1,1; 2,4; 3,6; 4,7 e 5,7 dS m-1) e dois cultivares de alface (Verônica e alface roxa, cv. Quatro Estações). As plantas cresceram bem em todos os níveis de salinidade, mostrando que as águas residuárias do processo de dessalinização podem ser usadas como fonte potencial de água para a produção hidropônica de alface, embora as perdas de produção tenham aumentado com a salinidade, $(6$ a $8 \%$ por unidade de condutividade elétrica), chegando a 28-35\% para a solução totalmente preparada com água de rejeito. O cv. Quatro Estações mostrou maior tolerância à salinidade do que Verônica.

Palavras-chave: Lactuca sativa L., água salina. ambiente protegido.

\section{ABSTRACT}

\section{Hydroponic lettuce production on coconut fiber using desalination wastewater}

The scarcity of good quality water has led to the necessity of using wastewater for irrigation in the semi-arid region of Brazil. This greenhouse experiment was carried out in the Universidade Federal Rural do SemiÁrido, located in Mossoro-RN, aiming to evaluate the use of wastewater from the reverse osmosis desalination process on lettuce (Lactuca sativa $\mathrm{L}$ ) production. The experiment was conducted in a randomized block design with three replications. Treatments were arranged in a 5 x 2 factorial scheme: five levels of salinity $\left(1.1,2.4,3.6,4,7\right.$ and $\left.5.7 \mathrm{dS} \mathrm{m}^{-1}\right)$ in the nutrient solution (according to the proportions of desalination of the wastewater in the nutrient solution: $0,25 \%, 50 \%, 75 \%$ and $100 \%$ ), and two lettuce cultivars: Verônica and Quatro Estações. Seedlings were planted in trays filled with coconut fiber as a substrate and allowed to growth for 24 days under hydroponic conditions, with different levels of salinity in the nutrient solution. The nutrient solution treatments were provided by a continuous flow rate drip irrigation system.

\footnotetext{
Recebido para publicação em 29/07/2010 e aprovado em 26/07/2011

${ }^{1}$ Extraída da dissertação de mestrado do segundo autor. Projeto de pesquisa financiado pelo CNPq.

${ }^{2}$ Engenheiro-Agrônomo, Doutor. Departamento de Ciências Ambientais e Tecnológicas, Universidade Federal Rural do Semi-Árido, BR 110 do Km 47, Costa e Silva, 59625-900, Mossoró, RN, Brasil.nildo@ufersa.edu.br. Autor para correspondência.

${ }^{3}$ Geólogo, Mestre. Departamento de Gestão Ambiental, Universidade Potiguar, Av. João da Escóssia, 1561, Nova Betânia, 59625-900, Mossoró, RN, Brasil. gilbertojale@ uol.com.br. ${ }^{4}$ Engenheiro-Agrônomo, mestrando, Universidade Federal Rural do Semi-Árido, BR 110 do Km 47, Costa e Silva, 59625-900, Mossoró, RN, Brasil. neto2006osvaldo@ yahoo.com.br. ${ }^{5}$ Engenheira-Agrônoma, Doutora. Departamento de Engenharia Agronômica, Universidade Federal de Sergipe, Avenida Marechal Rondon, s/n, São Cristovão, 49100-000, Aracajú, SE, Brasil. isisilva@gmail.com.

${ }^{6}$ Graduando em Agronomia. Universidade Federal Rural do Semi-Árido, BR 110 do Km 47, Costa e Silva, 59625-900, Mossoró, RN, Brasil.italosorac@hotmail.com; marialice6@hotmail.com
}

Rev. Ceres, Viçosa, v. 58, n.5, p. 632-637, set/out, 2011 
Total yield, fresh and dry mater, leaf number, and leaf area were recorded. Plants grew well in all levels of salinity showing that the wastewater from the desalination process can be a source of water for the hydroponic production of lettuce, although production losses increased with salinity (6 to 8\% per unit of electrical conductivity), reaching 28$35 \%$ for the solution fully based on wastewater. 'Quatro Estações' showed more tolerance to salinity than 'Veronica'.

Key words: Lactuca sativa L., greenhouse, water salinity.

\section{INTRODUÇÃO}

A irrigação com água subterrânea é uma alternativa para as comunidades inseridas no semiárido, a partir de investimentos públicos na perfuração de poços. Entretanto, essas fontes hídricas apresentam, na maioria dos casos, restrições de uso para o consumo humano por apresentarem problemas de salinidade (Ayers \& Westcot, 1999).

O tratamento amplamente utilizado para reduzir a concentração de sais destas águas tem sido a dessalinização (Porto et al., 2001); entretanto, faz-se necessário que se considerem os riscos ambientais decorrentes dessa técnica, porque, na dessalinização, gera-se, além da água potável, água residuária (rejeito) altamente salina e com risco de contaminação ambiental elevado.

Deste modo, o grande desafio da utilização do sistema de tratamento de água está na deposição ou reutilização da água de rejeito, de forma a evitar impactos negativos ao ambiente das comunidades que se beneficiam desta tecnologia. Conforme Mickley (2004), a escolha da melhor opção para se dispor o rejeito da dessalinização deve atender, dentre outros fatores, às disponibilidades locais (terra, compatibilidade das águas receptoras e distância), às disponibilidades regionais (geologia, leis estaduais, geografia e clima), ao volume de concentrado, aos custos envolvidos, à opinião pública e à permissibilidade.

Nas comunidades rurais de Mossoró, RN, onde têm sido implantadas as unidades de tratamento de água por dessalinização, o rejeito da dessalinização não está recebendo tratamento ou destinação adequada, sendo despejado diretamente ao solo e, quando utilizado na irrigação de culturas, não há qualquer fundamentação técnico-científica para o seu uso, causando problemas de salinização nos solos.

Os efeitos da salinidade sobre as plantas estão associados às dificuldades de absorção de água e toxicidade de íons específicos (Silva et al., 1999) e, ainda, à composição mineral das folhas com interferência nos processos fisiológicos (Bosco et al., 2009). Conforme observado por Shannon (1997), o grau em que o potencial osmótico in- fluencia o crescimento das plantas é dependente de muitos fatores, destacando-se a espécie vegetal, o cultivar, o estádio fenológico, a composição salina do meio e as condições edafoclimáticas. Além disso, informa Adams (1991) que a tolerância das plantas à salinidade é influenciada por diversos fatores, incluindo o estágio de crescimento para o tempo de exposição, duração da exposição, condição ambiental, tipo de substrato e sistema de produção.

No que concerne ao fator sistema de produção, as plantas cultivadas em hidroponia são mais tolerantes aos efeitos da salinidade do que as cultivadas nos sistemas convencionais, por causa da inexistência da matriz do solo (hidroponia tipo NFT) ou por ser relativamente inerte (hidroponia em substrato). Consequentemente, a absorção de água pelas plantas está condicionada apenas ao potencial osmótico, que reduz sua energia livre (Soares et al., 2006). Assim, os sistemas hidropônicos permitem o uso de água com maior condutividade elétrica, como por exemplo, as águas de rejeito de dessalinizadores, viabilizando uma atividade produtiva geradora de renda para as comunidades rurais com maior segurança ambiental.

Estudos realizados sobre a tolerância de várias espécies à salinidade, em sistema de cultivo hidropônico, têm demonstrado que, mediante manejos adequados da água e das práticas de cultivo, pode-se produzir comercialmente com água salina (Caruso \& Villari, 2004; Savvas et al., 2007; Al-Karaki et al., 2009).

Neste sentido, objetivou-se neste trabalho avaliar a utilização da água de rejeito da dessalinização no cultivo de alface, em sistema hidropônico, com fibra de coco e irrigação por gotejamento.

\section{MATERIAL E MÉTODOS}

O trabalho constituiu-se de um experimento com dois cultivares de alface, um do tipo crespo (Verônica) e outro roxo (Quatro Estações), conduzido em ambiente protegido, no Departamento de Ciências Ambientais, da Universidade Federal Rural do Semi-Árido (UFERSA), situado no município de Mossoró, RN (5 $5^{\circ} 11^{\prime}$ S, 37²0’W e 18 m), 
no período de maio a junho de 2008. Segundo a classificação de Köppen, o bioclima da região é do tipo BSwh', com temperatura média anual de $27,4{ }^{\circ} \mathrm{C}$, precipitação pluviométrica anual bastante irregular, com média de 672,9 mm, e umidade relativa de 68,9\% (Carmo Filho et al., 1991).

O ambiente protegido utilizado foi do tipo capela, com pé direito de $3,0 \mathrm{~m}, 12,0 \mathrm{~m}$ de comprimento e $16,0 \mathrm{~m}$ de largura, coberto com filme de polietileno de baixa densidade, com aditivo anti UV e espessura de 150 micras, protegido nas laterais com tela preta.

Foram testadas cinco misturas de água de rejeito da dessalinização e de abastecimento, para o preparo da solução nutritiva: $\left(\mathrm{M}_{1}=100 \%\right.$ água de abastecimento, $\mathrm{M}_{2}=$ $25 \%$ água de rejeito $+75 \%$ água de abastecimento, $M_{3}=$ $50 \%$ água de rejeito $+50 \%$ água de abastecimento, $\mathrm{M}_{4}=$ $75 \%$ água de rejeito $+25 \%$ água de abastecimento e $\mathrm{M}_{5}=$ água de rejeito coletada no dessalinizador). Após a adição dos fertilizantes, os valores da condutividade elétrica final das soluções nutritivas foram: 1,$1 ; 2,4 ; 3,6 ; 4,7$ e 5,7 $\mathrm{dS} \mathrm{m} \mathrm{m}^{-1}$, respectivamente.

A solução nutritiva foi preparada utilizando-se as águas das misturas, descritas anteriormente, e as seguintes quantidades de fertilizantes (por $100 \mathrm{~L}$ de solução): 50 $\mathrm{g}$ nitrato de cálcio, $37 \mathrm{~g}$ nitrato de potássio, $14 \mathrm{~g}$ de MAP, $27 \mathrm{~g}$ sulfato de magnésio e $6 \mathrm{~g}$ Quelatec $®$, para atender às necessidades nutricionais da cultura durante o ciclo da alface, conforme o recomendado para a região.

Cada parcela experimental era composta por um sistema hidropônico aleatório entre os blocos, constituído por uma canaleta de PVC, tipo trapézio, com $6 \mathrm{~m}$ de comprimento, tendo em sua base perfurações a cada $0,5 \mathrm{~m}$ para escoar o excesso de solução (Figura 1). As canaletas de cultivos foram preenchidas com substrato fibra de coco e colocadas a $0,90 \mathrm{~m}$ do nível do solo do ambiente protegido, fixadas por suporte de madeira, com declividade de aproximadamente $3 \%$, para facilitar a drenagem do excesso de solução nutritiva.

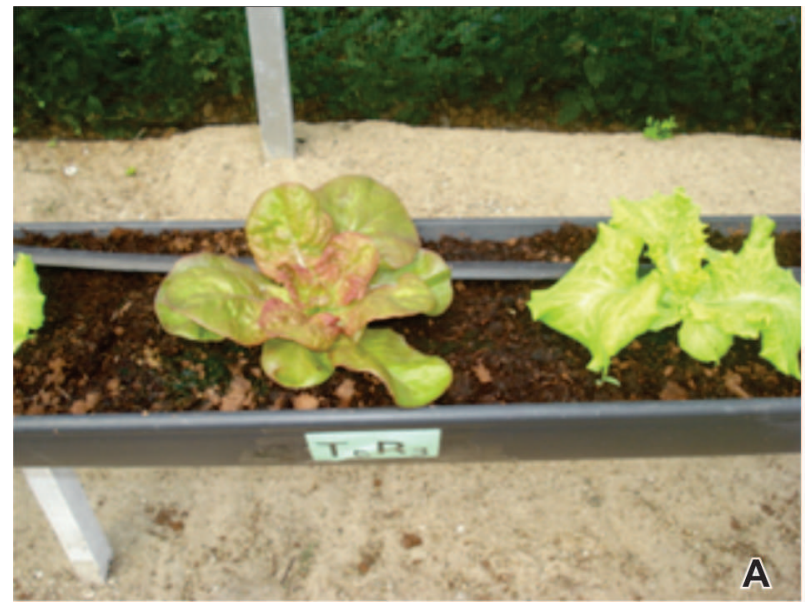

Para aplicar a solução nutritiva foi instalado, em cada tratamento, um sistema de irrigação, constituído por um tubogotejador, na superfície, com emissores espaçados de $0,5 \mathrm{~m}$ e vazão de $2,5 \mathrm{~L} \mathrm{~h}^{-1}$; um reservatório com capacidade para $500 \mathrm{~L}$ e uma eletrobomba, com componentes internos de plástico para evitar corrosão. O sistema de irrigação era acionado diariamente, até que a solução nutritiva começasse a escoar pelos orifícios. Ressalta-se que durante a condução do experimento as plantas não apresentaram sintomas visuais de deficiência hídrica.

As mudas de alface foram produzidas em bandejas de poliestireno, com 128 células, preenchidas com vermiculita, as quais flutuavam em solução nutritiva na mesa de germinação, sendo semeadas em 03/05/2008, duas sementes por cavidade. O desbaste foi realizado cinco dias após a emergência das plântulas, sendo mantida uma planta por célula. O transplante das mudas foi realizado aos 16 dias após a semeadura, quando as plantas apresentaram de 5 a $6 \mathrm{~cm}$ de altura e cinco folhas definitivas.

As mudas dos cultivares Verônica (crespa) e Quatro Estações (roxa) foram transplantadas alternadamente nas parcelas, coincidindo com o emissor, sendo essas distribuídas aleatoriamente por sorteio. As parcelas experimentais foram constituídas por canaletas com 12 plantas, as oito no centro ( 4 de cada cultivar) foram consideradas úteis e as duas plantas localizadas nas extremidades das canaletas designadas como bordadura. Foi utilizado o delineamento aleatório em blocos, com três repetições por tratamento.

Para monitorar o microclima no interior do ambiente protegido, foram instalados cinco psicrômetros não aspirados de termopar (cobre e constantan), todos em mesma posição em cada bancada, visando a medir possíveis variações na temperatura e umidade relativa, nas parcelas, ao longo do dia. As leituras de temperatura real do ar e umidade relativa foram feitas em intervalos de dez segundos, registrando-se em datalogger as médias a cada 30 minutos e as médias diárias.

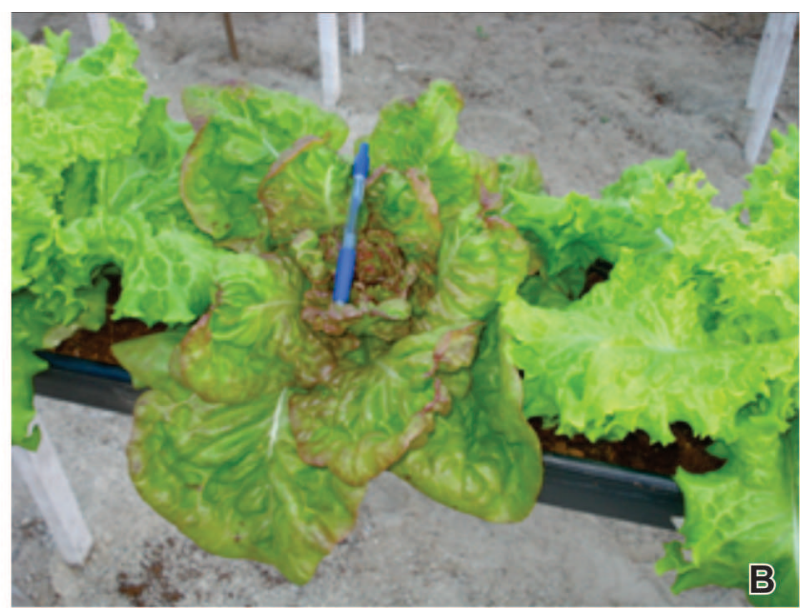

Figura 1 - Canaletas de PVC tipo trapézio utilizadas no experimento, preenchidas com fibra de coco (12 DAT (A) e 24 DAT (B)).

Rev. Ceres, Viçosa, v. 58, n.5, p. 632-637, set/out, 2011 
A colheita foi realizada aos 24 dias após o transplantio para a realização das análises de produção: número de folhas verdes maiores que 3,0 cm de comprimento (NF), desprezando-se as amareladas ou secas; diâmetro caulinar no momento da colheita (DC), determinado com um paquímetro digital; matéria fresca da parte aérea (MFPA); matéria seca da parte aérea (MSPA), determinada pelo peso seco em estufa com circulação forçada de ar, a $70{ }^{\circ} \mathrm{C}$, até atingir peso constante, e área foliar (AF), utilizando-se o integrador de área foliar, modelo LI-3100 da Licor. Os valores dos parâmetros de b e SL foram determinados com base no modelo de Maas e Hoffman (1977).

As produtividades percentuais da alface em função da salinidade em cada tratamento foram calculadas em relação à produtividade obtida com o tratamento testemunha. A análise estatística compreendeu análises de variância e de regressão.

\section{RESULTADOS E DISCUSSÃO}

A salinidade da solução nutritiva interferiu significativamente $(\mathrm{p}<0,05)$ na produção de matéria fresca da parte aérea (MFPA), para os dois cultivares de alface em sistema hidropônico, sendo observado um decréscimo na produção de matéria fresca com o aumento do percentual de água de rejeito salino adicionado na solução nutritiva (Figura 2A), com perdas de 35,54 e 28,27\%, respectivamente, para os cultivares Verônica e Quatro Estações, quando se utilizou solução nutritiva com $100 \%$ de água de rejeito $\left(\mathrm{CE}_{\mathrm{sol}}=5,7 \mathrm{dS} \mathrm{m}^{-1}\right)$ em relação $\left(\mathrm{CE}_{\mathrm{sol}}=1,1 \mathrm{dS} \mathrm{m}^{-1}\right)$.

Embora o cultivar Verônica tenha fornecido maior produção de matéria fresca em quase todos os níveis de salinidade da solução nutritiva, e, ainda maior valor de salinidade limiar $\left(\mathrm{SL}=1,28 \mathrm{dS} \mathrm{m}^{-1}\right.$ ), este se mostrou mais sensível que o cultivar Quatro Estações, com perdas unitárias de 8,04\% (b) de matéria fresca por aumento unitário de $\mathrm{CE}_{\text {sol }}$ acima da SL (Figura 2B). Na Figura 2B, verifica-se que os valores de "b" encontrados foram - 8,048 e - 5,913\%
$\left.(\mathrm{dS} \mathrm{m})^{-1}\right)^{-1}$ para os cultivares Verônica e Quatro Estações, respectivamente, o que indica a maior tolerância da alface à salinidade em sistema hidropônico, uma vez que Gervásio et al. (2000) encontraram valores de "b" respectivamente iguais a $-13,98$ e $-16,97 \%\left(\mathrm{dS} \mathrm{m}^{-1}\right)^{-1}$ para produção total e comercial para cultivo da alface em solo.

A salinidade da solução nutritiva interferiu significativamente $(\mathrm{p}<0,05)$ na produção de matéria fresca da parte aérea (MSPA), com variação menor na de matéria fresca, concordando com os valores verificados por Andriolo et al. (2005) e Soares (2007). Pode-se deduzir que houve perda no teor de água da parte aérea das plantas com o aumento da salinidade da solução nutritiva, concordando com os resultados de vários trabalhos conduzidos com a cultura da alface hidropônica sob níveis crescentes de salinidade da solução nutritiva (Tesi et al., 2003; Soares, 2007). Esse fato deve-se à resposta das plantas à salinidade, mediante sua capacidade de adaptação osmótica pela diminuição do teor de água nas folhas ou pelo aumento da concentração de solutos.

Para a MSPA a salinidade limiar foi estimada em 1,10 e $1,98 \mathrm{dS} \mathrm{m}^{-1}$ para os cultivares Verônica e Quatro Estações, respectivamente (Figuras $3 \mathrm{~A}$ e $3 \mathrm{~B}$ ). Foram observadas perdas de 22,57 e 25,69\% na MFPA, respectivamente, para os cultivares Verônica e Quatro Estações, para o tratamento com a adição de $100 \%$ de água de rejeito no preparo da solução em relação à testemunha.

O maior número de folhas (Figura 4) e a maior de área foliar da alface (Figura 5) foram observados para o cultivar Quatro Estações, em todos os níveis de salinidade, sendo o parâmetro número de folhas reduzido com o aumento da salinidade da solução nutritiva apenas para o cultivar Verônica, observando-se um aumento quadrático do número de folhas para o cv. Quatro Estações. Este reduziu, porém, a sua área foliar, com o incremento da salinidade da solução nutritiva, justificando a redução na produção de fitomassa seca e fresca da parte
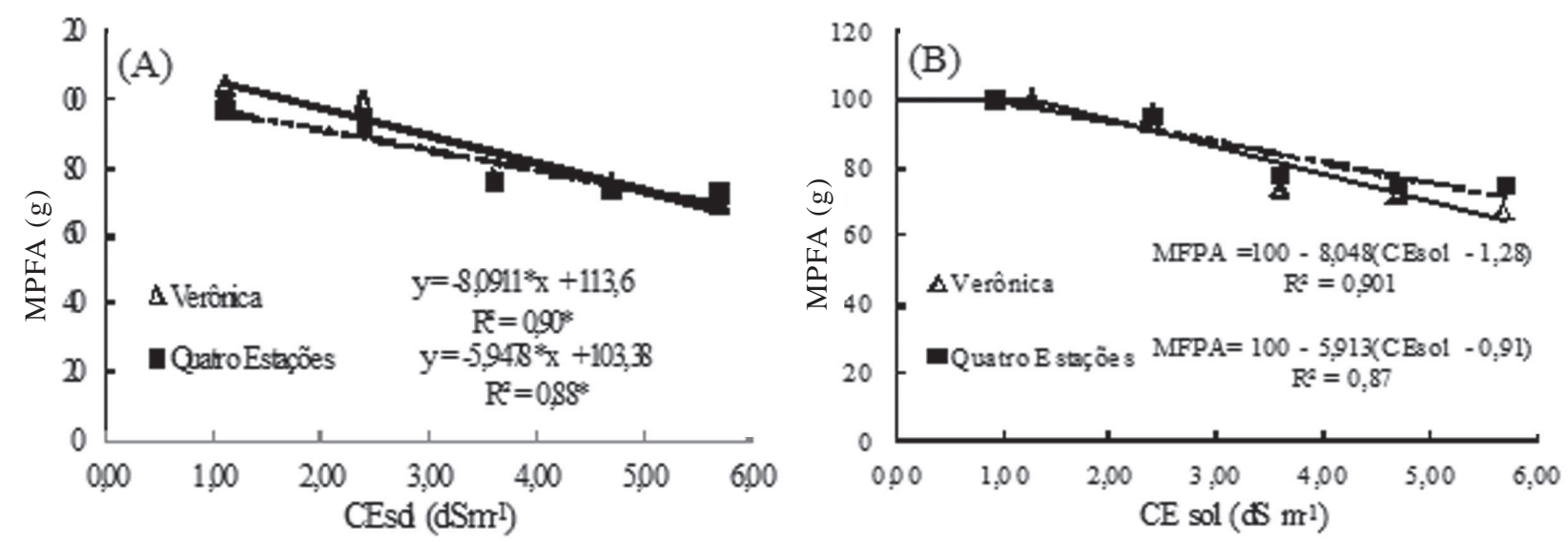

Figura 2. Efeito do aumento da salinidade na produção absoluta (A) e produção relativa (B) de matéria fresca da parte aérea de alface, cvs. Verônica e Quatro Estações, em cultivo hidropônico com fibra de coco. 

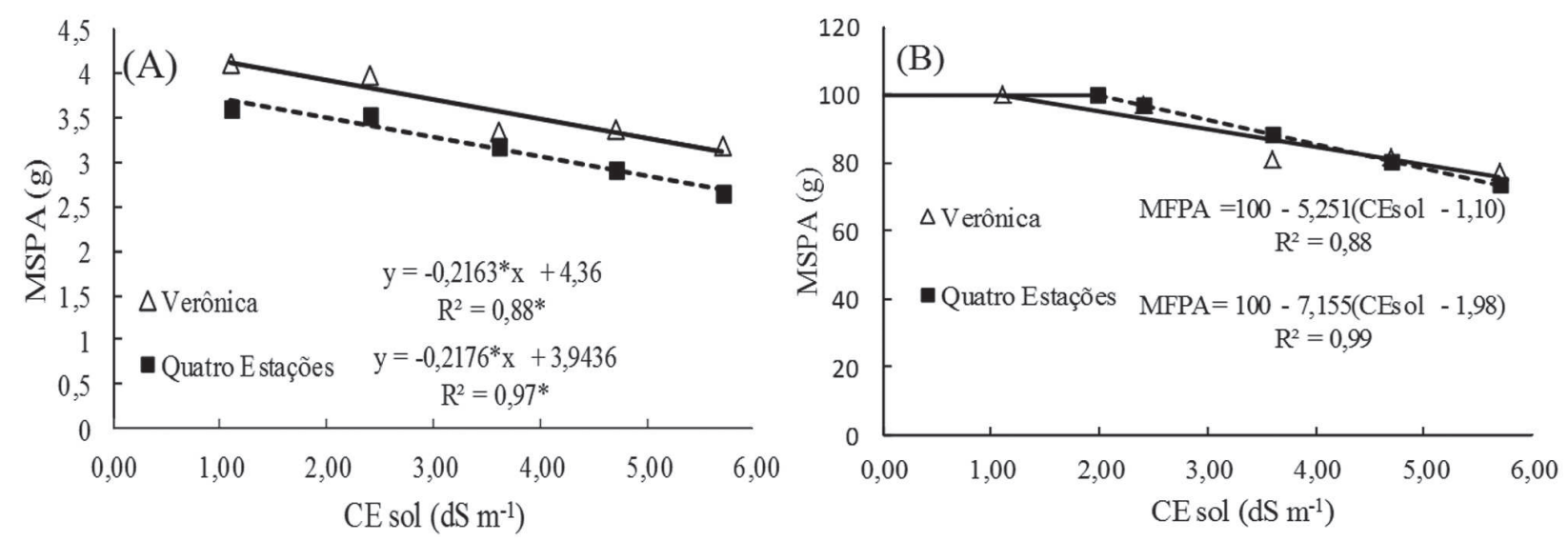

Figura 3. Efeito do aumento da salinidade na produção absoluta (A) e produção relativa (B) de matéria seca da parte aérea de alface, cvs. Verônica e Quatro Estações, em cultivo hidropônico com fibra de coco.

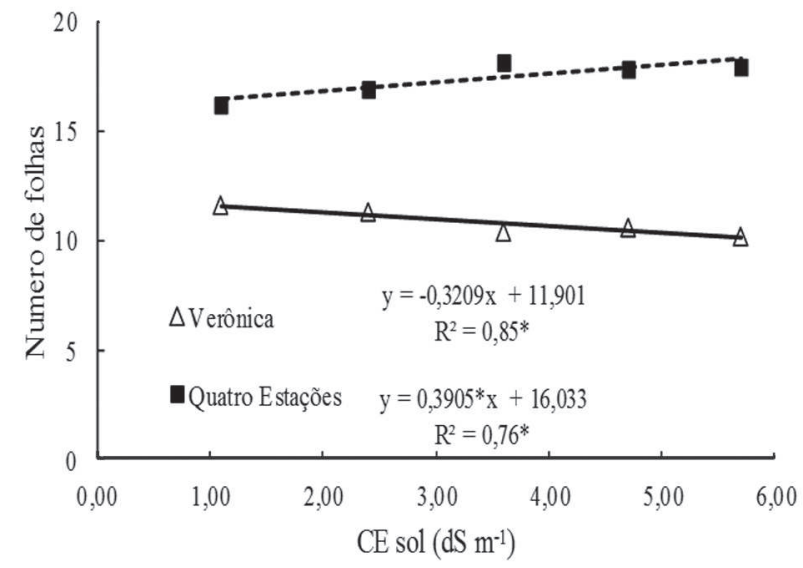

Figura 4. Efeito do aumento da salinidade sobre o número de folhas de alface cvs. Verônica e Quatro Estações, em cultivo hidropônico com fibra de coco.

aérea (Figuras 2A e 3B). Miceli et al. (2003) observaram a redução no número de folhas em hidroponia com fibra de coco nos dois cultivares de alface estudados (Severus e Ballerina), sob salinidade da solução nutritiva por adição de $\mathrm{NaCl}$.

Pode-se inferir que a produção de massas de matéria seca e fresca para os dois cultivares estudados, e o rendimento relativo decresceram suavemente com o aumento da condutividade elétrica da solução nutritiva, valores de b entre 5,25 e $8,04 \%\left(\mathrm{dS} \mathrm{m}^{-1}\right)^{-1}$.

$\mathrm{O}$ efeito reduzido da salinidade da solução nutritiva sobre as variáveis de crescimento pode ser atribuído ao sistema de cultivo hidroponia com fibra de coco, associado aos benefícios da produção sob condições protegidas (Buriol et al., 2000). Segundo Rosa et al. (2002), a fibra de coco tem alta capacidade de absorção hídrica, cerca de $85 \%$ de umidade, mantendo o substrato em condições ideais de umidade para reduzir os efeitos da salinidade da solução nutritiva. Além disso, no sistema hidropônico a inexistência do potencial matricial atuando sobre o potencial total da água reduz a dificuldade de

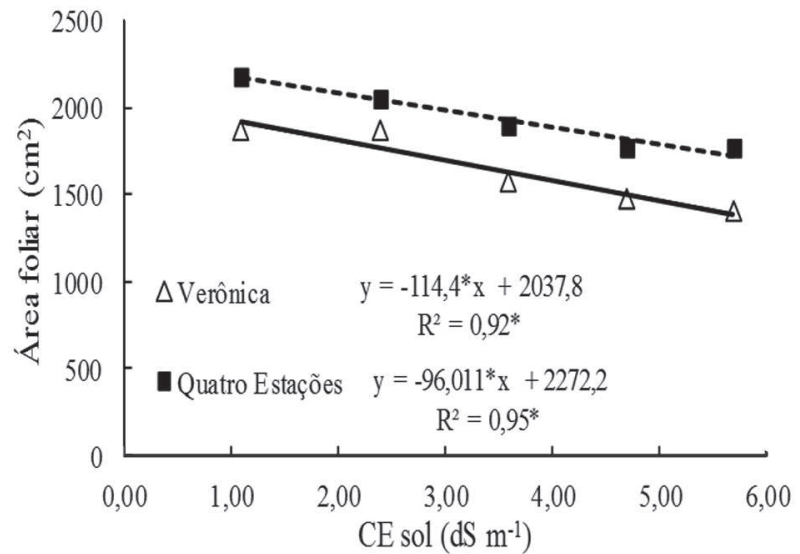

Figura 5. Efeito do aumento da salinidade na área foliar de alface cvs. Verônica e Quatro Estações, em cultivo hidropônico com fibra de coco.

absorção de água pelas plantas em meio salino, conforme relatado por Soares (2007). Esta constatação justificaria a destinação adequada do rejeito salino, possibilitando a produção de alimentos e a maior segurança ambiental das comunidades que se beneficiam da tecnologia da dessalinização.

\section{CONCLUSÕES}

As águas salobras da dessalinização podem ser utilizadas no preparo de solução nutritiva, com perdas de rendimento comercial da alface hidropônica em fibra de coco abaixo de $8 \%$ por unidade de CE.

O cultivar 'Quatro Estações' mostrou-se mais tolerante à salinidade da água do rejeito, em relação ao cultivar 'Verônica'.

\section{AGRADECIMENTOS}

Os autores agradecem ao Conselho Nacional de Pesquisa e Tecnologia (CNPq), pelo financiamento deste projeto de pesquisa. 


\section{REFERÊNCIAS}

Adams P (1991) Effects of increasing the salinity of the nutrient solution with major nutrients or sodium chloride on the yield, quality and composition of tomates grown in rockwool. Journal Horticulture Science, 66:201-207.

Al-Karaki G, Al-Ajmi A \& Othman Y (2009) Response of soilless grown bell pepper cultivars to salinity. Acta Horticulturae, 807:227-232.

Andriolo JL, Luz GL, Witter MH, Godoi RS, Barros GT \&. Bortolotto OC (2005) Growth and yield of lettuce plants under salinity. Horticultura Brasileira, 23:931-934.

Ayers RS \& Westcot DW (1999) A qualidade da água na agricultura. $1^{\circ}$ ed. Campina Grande, UFCG. 218 p.

Bosco MRO, Oliveira AB, Hernandez FFF \& Lacerda CF (2009). Influência do estresse salino na composição mineral da berinjela. Revista Ciência Agronômica, 40:157-164.

Buriol GA, Schneider FM, Estefanel V, Andriolo JL \& Medeiros SLP (2000) Modificação da umidade relativa do ar pelo uso e manejo da estufa plástica. Revista Brasileira de Agrometeorologia, 8:11-18.

Carmo Filho F, Espínola Sobrinho J \& Maia Neto JM (1991) Dados meteorológicos de Mossoró (janeiro de 1989 a dezembro de 1990). Mossoró, FGD. 110 p. (Coleção Mossoroense, Série 630C).

Caruso G \& Villari G (2004) Effect of EC-level and plant shading on the NFT-grown "Friariello Pepper". Acta Horticulturae, 659: 576-585.

Gervásio ES, Carvalho JA \& Santana MJ (2000) Efeito da salinidade da água de irrigação na produção da alface americana. Revista Brasileira de Engenharia Agrícola e Ambiental, 4:125-128.

Maas EV \& Hoffman GJ (1997) Crop salt tolerance - Current assessment. Journal of Irrigation and Drainage, 103:115-134.

Miceli A, Moncada A \& D'anna F (2003) Effect of salt stress in lettuce cultivation. Acta Horticulture, 609:371-375.

Mickley MC (2004) Desalination concentrate management and issues in the United States. Disponível em: <http:// www.twdb.state.tx.us/Desalination/Desal/proceedings / Mickley.pdf. Acessado em: $30 \mathrm{de}$ dez 2004.

Porto ER, Amorim MCC \& Silva Júnior LGA (2001) Uso do rejeito da dessalinização de água salobra para irrigação da ervasal (Atriplex nummularia). Revista Brasileira de Engenharia Agrícola e Ambiental, 5:111-114.

Rosa MF, Santos FJS, Montenegro AAT, Abreu FAP, Correia D \& Araújo FBS (2002) Caracterização do pó da casca de coco verde usado como substrato agrícola. Fortaleza, Embrapa-CNPAT, 6p. (Comunicado Técnico, 54).

Savvas D, Stamatib E, Tsirogiannisb IL, Mantzosb N, Barouchasb PE, Katsoulasc N \& Kittas C (2007) Interactions between salinity and irrigation frequency in greenhouse pepper grown in closed-cycle hydroponic systems. Agricultural Water Management, 91:102-111.

Shannon MC (1997) Adaptation of plants to salinity. Advances in Agronomy, 60:75-120.

Silva EFF, Duarte SN, Furlan RA, Ferreira YRP \& Miranda JH (1999) Utilização de águas com diferentes níveis de salinidade na irrigação da alface. Revista de Horticultura Brasileira, 17:327.

Soares TM, Silva IJO, Duarte SN \& Silva EFF (2006) Destinação de águas residuárias provenientes do processo de dessalinização por osmose reversa. Revista Brasileira de Engenharia Agrícola e Ambiental, 10:730-737.
Soares TM (2007) Utilização de águas salobras no cultivo da alface em sistema hidropônico NFT como alternativa agrícola condizente ao semi-árido brasileiro. Tese de Doutorado, Escola Superior de Agricultura "Luiz de Queiroz", Piracicaba, 268 p.

Tesi R, Lenzi A \& Lombardi P (2003) Effect of salinity and oxygen level on lettuce grown in a floating system. Acta Horticulturae, 2: 383-387. 